\title{
Remittances, expenditure patterns, and gender: parametric and semiparametric evidence from Ecuador
}

\author{
Kristin Göbel
}

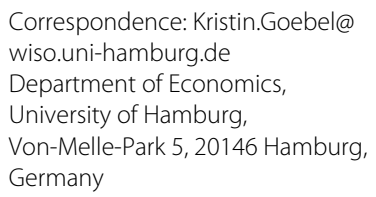

Correspondence: Kristin.Goebel@ wiso.uni-hamburg.de

Department of Economics, University of Hamburg, Von-Melle-Park 5, 20146 Hamburg, Germany

\begin{abstract}
This study estimates the impact of migrants' remittances on households' spending decisions in Ecuador. Applying both parametric and semiparametric techniques, we find strong evidence that remittances enhance expenditures on education, health, and housing, but decrease expenditures on food. This supports the hypotheses that these inflows result in a stronger human capital accumulation and therefore improve the long-run production possibilities. We do not find strong differences in the impact on expenditure patterns of male and female household heads. The sex of the remitter and the receiver affects the expenditure behavior only slightly.
\end{abstract}

JEL Codes: C14, C34, D12, F24, J16

Keywords: Ecuador, Remittances, Household consumption, Gender

\section{Introduction}

Ecuador has experienced a massive emigration which is mainly motivated by economic factors. After several crises, and therefore high poverty, unemployment, and few economic prospects, the emigration rate increased strongly since the end of the 1980s. Destination countries are the United States and Europe, especially Spain. Current emigration from Ecuador is mostly illegal and therefore expensive and permanent. A migrant has to pay to a facilitator between US\$10,000 and US\$ 14,000 to travel to the United States (Soruco et al. (2008)). Often the whole family takes a loan to finance migration, and first remittances are often used for repaying these loans. Main motivation for most of the Ecuadorian migrants is thus not the prospect of a better life in another country, but the possibility to provide financial support for relatives in the home country (Pew Hispanic Center and Benedixen and Associates (2003)).

Migration and migrants' remittances take an important position in the economy of Ecuador. In 2006, remittances account for 7 percent of GDP. The inflows have the potential to reduce poverty, liquidity constraints, and income volatility. Moreover, they can increase household expenditures on education and health, categories which are considered as especially important for economic development. Women form an increasing part of the migratory movement, whether as migrants, who send remittances, or as head of the households, who receive international transfers. The impact of remittances depends mainly on their use, and the literature suggests gender-specific preferences in the use

(c) 2013 Göbel; licensee Springer. This is an Open Access article distributed under the terms of the Creative Commons Attribution License (http://creativecommons.org/licenses/by/2.0), which permits unrestricted use, distribution, and reproduction in any medium, provided the original work is properly cited. 
of income. The aim of this study is to examine, whether remittances-receiving households have higher expenditures on education and health, and how this relationship is affected by female bargaining power. To this end, we evaluate the impact of (i) remittances on households' expenditure patterns, (ii) the gender of the household head who receives remittances, and (iii) the gender of the individual who sends and who receives remittances.

The remainder of this study is organized as follows. The next section briefly summarizes the impact of remittances on development. It also examines the most salient results from the intra-household expenditure literature. Section three presents the data. Section four describes the empirical approach, and the parametric and semiparametric estimation procedures in particular. Moreover, the econometric strategies to identify the impacts of remittances and gender are explained. The fifth section discusses the results and relates them to the literature. The final section concludes.

\section{Remittances and gender}

International migrants moving from developing to developed countries get acquainted with a different society, other social norms, and new markets in the destination countries. Their preference on the use of income may change, and so may the expenditure behavior of the households in the home country. Several studies indeed find that remittance receipt increases household expenditures on education and health (a detailed review will be given in section 5.1), categories which are considered as especially important for economic development. On the one hand, remittances decrease liquidity constraints, and therefore allow households to invest more in the education of their children, as well as they reduce the need for child labor (McKenzie and Rapoport (2011)). Due to their counter-cyclical nature the international transfers reduce income risk and smooth consumption. Especially when capital markets are weak this is important to allow investments in human capital (Calero et al. (2009)). An additional important factor influencing the labor force is health. Empirical evidence suggests an increase due to remittance receipt which is partly explained by an increased knowledge about health related issues (Hildebrandt and McKenzie (2005); López-Córdova et al. 2005).

Migration and remittances are expected to change the bargaining power within the family which may affect the allocation of household expenditures. In the traditional unitary-household theory, households are units that have a sole preference and pool all resources. However, every member of the household has own preferences. If a household contains more than one individual, the individual consumption depends on the bargaining power (Duflo and Udry (2004)). Several empirical studies have tested the unitary household theory. Although the impact differs between countries, there is still a common structure: more resources controlled by women enhance expenses on household wellbeing, especially those for children and on education increase (Mason and King (2001); Quisumbing and Maluccio (2000)). Using data from Cote d'Ivoire, Hoddinott and Haddad (1995) find evidence that a greater share of household' income controlled by women results in more expenditures on food, and less on alcohol and cigarettes. These results are in line with the findings from a study of Doss (2006). Moreover, not only the share of expenditure devoted to food or education increases with a higher female bargaining power, but also the corresponding outcomes improve such as infant mortality, schooling or nutrition (Thomas (1990)). In a nutshell, a strong female intra-household 
bargaining power seems to increase expenses on education, health, and food. This is one reason for development approaches to focus on transferring income to women. Women marry at an earlier age, have a higher life-expectancy, and therefore outlive their husbands. As they have to rely on their children for old-age support during a longer period, this behavior is rational (Quisumbing and Maluccio (2000)).

Summing up the literature that focuses on gender-specific motivations for remittances, women seem to function as insurers for their families and tend to prefer their remittances to be spent on education and health, while male remitters prefer investments in housing and other assets (see for a review Guzmán et al. (2008)). Though the migrant may intend his/her remittances to be spent in a certain way, he/she is not physically present in the origin household and cannot fully monitor his behavior (a typical principal-agent problem). Hence, the use of remittances reflects the preferences of the remitter and the receiving household. In a Mexican case study, for example, Pfeiffer and Taylor (2008) reveal that households with a female remitter invest a smaller share of total expenditures on education than households with a male remitter. This stands in contrast to the assumption that female remitters prefer their remittances to be spent on education. The authors conclude that this result may be due to the intra-household bargaining power: since women cannot monitor the education of their children, female migration leads to smaller expenses on education, in spite of remittances.

\section{Data}

This study uses data from the Living Standards Survey round five in Ecuador Encuesta Condiciones de Vida - Quinta Ronda (ECV-5), collected by the National Statistic and Census Institute (INEC) in 2005/2006. The data set comprises 13,581 households. In the following analysis, households from the Amazonas region are excluded which reduces the sample slightly to 12,491 households. ${ }^{1}$ Incomes and expenditures have been collected in annual, monthly, weekly, and daily values, and we convert all amounts to an annual level. Several households receive numerous products for free, which is especially true for food products and poor households. Due to poverty, food is often grown in private gardens or received from the employer as remuneration. Consequently, these households have small expenditures on food. Yet, monetary values for these costless products are available. In the estimation sample, we count them twice, once as income and at the same time as expenditure. ${ }^{2}$ We aggregate expenditure data from the survey into two consumption categories (food and housing), two types of human capital investment (education and health) and one other (miscellaneous) category (see Table 1 for more details on the categories). We restrict the empirical analysis to households with positive expenditures on food and housing (which reduces the sample size very slightly to 12,488 observations).

Table 1 Dependent variables

\begin{tabular}{lllll}
\hline Variable & Definition & Examples & Mean & $\mathbf{0}^{*}$ \\
\hline Food & Purchases and non-purchased food & Bread, milk, gifts & 0.50 & 0.00 \\
Housing & Real estates, rent with related costs & Rent expenses, water, gas & 0.18 & 0.00 \\
Education & Educational expenses & Registration fees, books & 0.03 & 0.10 \\
Health & Health expenses & Doctor fees, medicine & 0.05 & 0.34 \\
Other & Miscellaneous & Durable goods, luxuries & 0.24 & 0.00 \\
\hline
\end{tabular}

Source: Authors' analysis based on the ECV-5.

Note: $\%$ of households have zero expenditure in this category. 
Although the survey provides detailed data on socio-demographic characteristics, it is not a specialized survey of remittances or migration. Therefore, it does not contain comprehensive data on migrants. Only migrants that have left the country after 2000 are captured by the survey, and basic data such as age, gender, education, and destination country are available. These migrants (560 men and 470 women) tend to be more educated than the Ecuadorian average, and female migrants have a higher educational level than their male counterparts. Spain is the main migration destination, accounting for 47 (58) percent of all male (female) migrants. The United States attract 40 percent of all male, but only 24 percent of all female migrants. These gender-specific migration flows result from a gender-specific demand in the destination countries. ${ }^{3}$ Almost half (45 percent) of the migrants (of both genders) leave minor children in the responsibility of the households in Ecuador. This may partly explain the high incidence of remittances: 76 (74) percent of the households with a male (female) migrant receive the inflows. International transfers to households with a male migrant are substantially higher (US\$2040) than those towards households with a female migrant (US\$ 1500). ${ }^{4}$ Yet, households do not explicitly indicate the remitter. If a male household member has migrated after 2000, one may assume the remitter to be male. Conversely, it may be that not the male migrant is the remitter, but is in fact another person who migrated before 2000.

The effect of migration on expenditure patterns cannot be observed due to the lack of data on migrants. However, the impact of remittances can be evaluated, since the data set contains comprehensive information on remittances, including the amount remitted, the frequency in which remittances are received, as well as the source country. An additional analysis of the impact of the gender of the migrant on expenditure patterns can be drawn on a subsample of 616 households. These households receive remittances and have household members who migrated after 2000.

Table 2 shows descriptive statistics from the ECV-5, disaggregated by gender and remittance receipt. Of the 12,491 households included in the sample, 16 percent receive remittances. In terms of gender, 21 percent of the households in the sample are female headed, and differences in comparison with male headed households are present; while per-capita expenditures are similar in non-receiving households (US\$1520), women have a higher expenditure level in remittance receiving households (US\$ 1640 and US\$1800,

Table 2 Descriptive statistics

\begin{tabular}{|c|c|c|c|c|c|c|}
\hline \multirow[t]{2}{*}{ Remittance receipt } & \multicolumn{2}{|c|}{ All households } & \multicolumn{2}{|c|}{ Male-headed hh. } & \multicolumn{2}{|c|}{ Female-headed hh. } \\
\hline & No & Yes & No & Yes & No & Yes \\
\hline Per-capita expenditures & 1517 & 1695 & 1517 & 1641 & 1517 & 1803 \\
\hline Household size & 4.06 & 4.20 & 4.24 & 4.45 & 3.27 & 3.71 \\
\hline No. females $>=15$ & 1.34 & 1.56 & 1.29 & 1.48 & 1.58 & 1.72 \\
\hline No. males $>=15$ & 1.28 & 1.26 & 1.44 & 1.58 & 0.62 & 0.61 \\
\hline No. children $<15$ & 1.43 & 1.38 & 1.52 & 1.39 & 1.06 & 1.38 \\
\hline No. adults $>=15$ with prim. educ. & 1.22 & 1.14 & 1.27 & 1.23 & 0.99 & 0.94 \\
\hline No. adults $>=15$ with sec. educ. & 0.73 & 0.91 & 0.77 & 1.00 & 0.59 & 0.72 \\
\hline No. adults $>=15$ with tert. educ. & 0.40 & 0.57 & 0.42 & 0.63 & 0.34 & 0.46 \\
\hline Household head married (\%) & 72.78 & 65.79 & 87.97 & 87.03 & 7.93 & 24.03 \\
\hline Partner of hh. head absent (\%)* & 1.26 & 12.54 & 0.73 & 2.01 & 25.95 & 87.58 \\
\hline Observations & 10,503 & 1,988 & 8,510 & 1,318 & 1,993 & 670 \\
\hline
\end{tabular}

Source: Authors' analysis based on the ECV-5.

Note: * given that the head is married. 
respectively). Female headed households have one family member less, the head is rarely married, and if she is, the partner is absent in most cases. The incidence of female household heads is about twice as high in remittance-receiving household. Women seem to be head of the household only if there has never been a husband, if he died, or if he migrated and sends remittances.

\section{Econometric analysis}

\subsection{Empirical approach}

How remittances affect development depends mainly on their use. The aim of this study is to examine whether remittances-receiving households have higher expenditures on education and health, and how this relationship is affected by female bargaining power. Several previous studies have contributed to a pessimistic perception by observing that the inflows are mainly used for food and current expenses (for a review, see Chami et al. (2003)). Yet, remittances - like any other source of income - are fungible and increase total income. Even if they are not directly invested in human capital, they can lower liquidity constraints, and hence other sources of income may be invested. Thus, the whole expenditure pattern of the households has to be examined. Recent studies include a remittances variable as a regressor in a system of household demand equations (e.g. Zarate-Hoyos (2004), Taylor and Mora (2006) and Adams and Cuecuecha (2010)). An advantage of this approach is its consistency with consumer demand models which assume that income from diverse sources is pooled. One disadvantage is the potential endogeneity of remittances, which has to be addressed. Migration (and consequently remittance receipt) selects on both, observable and unobservable characteristics. To address the endogeneity of remittances, an instrumental variable (IV) approach is applied.

After analyzing the impact of remittances on household's budget allocation, a genderdimension is taken into account. The first challenge is to find a variable that measures intra-household bargaining power. Exogenous variables typically used to measure female bargaining power, like wealth upon marriage, are not stated in the ECV-5. Following Guzmán et al. (2008), the best proxy available is the sex of the household head. However, the gender of the household head is correlated with explanatory variables which implies that gender (as remittances) is endogenous. As no reasonable instrument for gender exists, we apply a matching procedure to make male and female headed households comparable, and run separate regressions.

In the third part of the analysis, the impact of the gender of the migrant and the receiver is evaluated. To this end, we focus on a subsample of 616 remittance-receiving households with migrants. Here, the mentioned principal-agent problem can arise as the household in the home country is in fact spending the transfer. In spite of possibly gender-specific preferences of the migrants, these may not be reflected in the use of remittances.

\subsection{Econometric model}

In the empirical analysis, a proper functional form for the econometric model has to be chosen. A popular form is the Working-Leser curve which relates budget shares linearly to the logarithm of total household expenditures and additional variables (Working (1943); Leser (1963)). ${ }^{5}$ In this study, the model is specified as follows:

$$
w_{i j}=\alpha_{i}+\beta_{i} \log \frac{x_{j}}{n_{j}}+\psi_{i} \log \left(n_{j}\right)+\eta_{i} \Pi_{j}+\theta_{i} R_{j}+\epsilon_{i j},
$$


or in a shorter notation

$$
w_{i j}=\mu_{i} X_{j}+\epsilon_{i j}
$$

where $w_{i j}$ is the budget share of expenditure category $i$ by household $j, x_{j}$ is total household expenditures, $n_{j}$ is household size (thus $\frac{x_{j}}{n_{j}}$ is per-capita expenditures). The term $\Pi_{j}$ is a vector of household characteristics that may affect expenditure behavior, $R_{j}$ captures whether the household receives remittances, and $\epsilon_{i j}$ is an error term. In the short notation $X_{j}$ represents all right hand side variables of the model including the intercept. The dependent variables reflect the categories of household expenditures, namely "food", "housing", "education", and "health". Not every household has expenditures on each category which implies censored dependent variables. Expenditure on a category is observed only if the household's desired expenditure exceeds some threshold which depends on the lumpiness of the goods as well as the opportunity cost. Estimation techniques that fail to consider the censoring of the dependent variables give rise to biased parameter estimates. Thus, the following participation equation is added to equation (2):

$$
w_{i j}^{*}=\gamma_{i} Z_{j}+u_{i j}
$$

The dependent variable $w_{i j}^{*}$ is unobservable, but has an observable realization of one if $w_{i j}$ takes on a positive value and zero otherwise. The term $Z_{j}$ is a vector that contains all explanatory variables included in equation (2), and some additional variables which allow for identification, and $u_{i j}$ is an error term. ${ }^{6}$ In addition, the budget shares are not independent of each other. A positive shock in the budget share "food", for example, results in higher expenses on "food" which leads to smaller expenses in at least one other budget share. The error terms across equations are correlated. The model is an equation system with dependent variables censored by latent variables.

Estimating a censored system of equations is no easy task. Until 1999, the popular Heien and Wessells (1990) two-step estimation procedure was considered the standard approach. Yet, Shonkwiler and Yen (1999) (henceforth SY) point out an inconsistency and show that this estimator performs poorly in Monte Carlo simulations. They hence suggest an alternative, consistent two-step estimator which has found wide applicability in empirical work as it has a solid theoretical foundation and is easy to implement. In the first step, the probability of participation in each expenditure category is estimated using a probit regression. The results are then used in the second step, to weight the expenditure equations in the system, and to construct a selection term. Despite its popularity, this method has been criticized, since it relies on the assumption that the residuals follow a normal distribution, and are homoscedastic in the participation equation. Any violation of the assumptions will result in biased and inconsistent estimation results. Sam and Zheng (2010) (henceforth SZ) hence propose a two-step estimator similar in spirit to SY that uses Klein and Spady (1993) (hereafter denoted by KS) semiparametric single-index model instead of a probit regression in the first step. The semiparametric KS estimator makes no distributional assumptions, but it assumes a linear index function to avoid the curse of dimensionality. Being asymptotically efficient in the sense that it attains the semiparametric efficiency bound, it is the most efficient two-step estimator compared to other semiparametric estimators. Moreover, KS perform Monte Carlo simulations which indicate that their estimator is considerably more accurate than a probit estimation when the 
errors are not normally distributed. In contrast, the efficiency losses are modest when the error distribution is standard normal.

Both methods start with an estimation of the participation equations:

$$
P\left(w_{i j}^{*}=1 \mid Z_{j}\right)=F_{i}\left(\gamma_{i} Z_{j}\right) .
$$

Whereas the probit model assumes $F_{i}(\cdot)$ being the normal cumulative distribution function (cdf), the semiparametric method estimates the coefficients $\hat{\gamma}_{i}$ and the unknown continuous distribution function $\hat{F}_{i}(\cdot){ }^{7}$ The estimate of $\gamma_{i}$ is obtained by maximizing the quasi-loglikelihood function:

$$
l\left(\gamma_{i}\right)=\sum_{n=1}^{N}\left(w_{i j}^{*} \log \left(\hat{F}_{i}\left(\gamma_{i} Z_{j}\right)\right)+\left(1-w_{i j}^{*}\right) \log \left(1-\hat{F}_{i}\left(\gamma_{i} Z_{j}\right)\right)\right) .
$$

In the second step, the following system of equations is estimated:

$$
w_{i j}=\hat{F}\left(\hat{\gamma}_{i} Z_{j}\right)\left(\mu_{i} X_{j}+\lambda_{i}\left(\hat{\gamma}_{i} Z_{j}\right)\right)+\varepsilon_{i j},
$$

where all variables are defined as before, and $\lambda_{i}(\cdot)$ is a selection control function. If the error term is normally distributed (SY), $\lambda_{i}(\cdot)$ is simply the Heckman (1979) control term

$\theta_{i} \frac{\phi\left(\hat{\gamma}_{i} Z_{j}\right)}{\Phi\left(\hat{\gamma}_{i} Z_{j}\right)}$, where $\Phi(\cdot)$ denotes the cdf, $\phi(\cdot)$ is the normal probability density function (pdf), and $\theta_{i}$ are coefficients to be estimated.

Applying the SZ method, $\lambda_{i}(\cdot)$ is unknown because the distribution of the error terms is not specified. To estimate the control term, Newey (1999) approximates $\lambda_{i}(\cdot)$ with a power series expansion of the transformed index $\tau_{i j}=f\left(\hat{\gamma}_{i} Z_{j}\right)$. That is

$$
\lambda_{i}(\cdot)=\sum_{k=1}^{K} \theta_{i k} \tau_{i j}^{k-1}=\left(1, \theta_{i 2} \tau_{i j}, \theta_{i 3} \tau_{i j}^{2}, \ldots, \theta_{i K} \tau_{i j}^{K-1}\right),
$$

where the first term cannot be identified separately from the constant term. Here, the order $K$ is chosen such as to minimize the mean squared error for each equation.

We use a power series of inverse Mill's ratio of the normalized estimated index. ${ }^{8}$ The semiparamteric estimator imposes a scale and location normalization for identification. To reverse it, we use the constant and slope coefficients, $\pi_{0}$ and $\pi_{1}$, respectively, that we obtain from a probit estimation of $w_{i j}^{*}$ on the index $\left(\hat{\gamma}_{i} Z_{j}\right)$. The inverse Mill's ratio of the normalized estimated index is then:

$$
\tau_{i j}=\phi\left(\hat{\pi}_{0}+\hat{\pi}_{1}\left(\hat{\gamma}_{i} Z_{j}\right) / \Phi\left(\hat{\pi}_{0}+\hat{\pi}_{1}\left(\hat{\gamma}_{i} Z_{j}\right)\right) .\right.
$$

The first order term is hence the Heckman correction, and will be sufficient if the error term is normally distributed.

The SZ method assumes a more general form of equation (4). Therefore, it has the advantages of generating consistent and efficient estimates without relying on distribution assumptions, and accommodating a certain form of heteroscedasticity. Since semiparametric methods are extremely computationally demanding, the SY method is preferred if its assumptions are not violated. To exploit the information contained in the cross equation error correlations, the system of equations is estimated jointly for the full household sample using iterative nonlinear SUR (with both methods). ${ }^{9}$

\subsection{Endogeneity of remittances}

In a thought experiment whereby a number of households are randomly drawn from the population, and subsequently "treated" with remittance receipt, the impact of remittances 
on household expenditure patterns could be examined. As such an experiment is not possible, the problem of endogeneity arises, i.e. the variable remittance receipt is correlated with the residual. Migration of one household member is a precondition for the receipt of remittances. The occurrence of one member migrating depends heavily on household characteristics. Variables that may "explain" migration may also be correlated with household expenditure patterns. These variables may include observable characteristics, such as household income and the educational level, as well as unobservable characteristics like the degree of risk aversion or ambition. In the absence of random assignment, an estimation strategy that allows for identification of the treatment effect has to be employed, such as a matching procedure, difference-in-difference estimation or an instrumental variable (IV) approach. McKenzie et al. (2010) use a natural experiment to compare different methods in estimating the income gains from migration. Their findings suggest that migration selects on both, observable and unobservable characteristics, and that an IV approach with good instruments works best among the non-experimental methods.

Although an IV approach is preferable, it relies heavily on the exogeneity assumption. Variables which explain remittance receipt but are uncorrelated with the expenditure patterns have to be employed. In this study, identification of the causal effect (the local average treatment effect LATE) relies on instruments that exploit information on former remittance receipt within the community. From the ECV-4, the previous round of the survey, we construct the variable "Remittances in the community in 1999" which is the proportion of remittance receiving households in the community in the year 1999. This variable is interacted with the proportion of household members with secondary and tertiary education, respectively, to allow for the variability of the instrument at the household level (Amuedo-Dorantes and Pozo (2006); Hanson and Woodruff (2003)). Justification lies in the fact that historical migration developed networks which can promote future migration. On the other hand, historical migration rates are exogenous as they occurred in the past, and are hence not affecting current consumption.

\subsection{Endogeneity of gender}

Next, we turn to the gender-dimension of our analysis. Table 2 has already shown that household characteristics differ substantially for female and male headed households. The gender of the household head is likely to be correlated with the residual, i.e. gender is endogenous. The impact of remittances will be different even in the absence of genderspecific preferences. To make female and male headed households comparable, this study uses a matching procedure. ${ }^{10}$ The idea behind matching is to find for each "treated" observation (i.e. female headed household) its "non treated" or "control" counterpart (i.e. male headed household) with equal characteristics. If the number of variables is large or variables take on many values (like total per-capita expenditures here), exact matching becomes impossible. Common practice is then to use some form of inexact matching that balances the covariates as well as possible. The idea of coarsened exact matching (CEM) developed by Blackwell et al. (2009) is to coarsen each variable into groups, for example, we split total household expenditures by quartile. Subsequently, a set of strata is created which contain all observations with the same values of the coarsened data. One possible stratum hence may contain all individuals from the first expenditure quartile, which live in an urban area, have no children, etc.. Observations in strata that contain at least one treated and one control unit are retained, and units in the remaining strata are removed 
from the sample. If a stratum does not contain the same number of treated and control units, observations are randomly dropped to obtain the same number.

\section{Results}

\subsection{The impact of remittance receipt}

To address the possible problem of endogeneity, the probability of remittance receipt is estimated in the first stage (see the first column of Table 3). The probability increases with per-capita expenditures; migration is very expensive, only wealthier households can afford it, and consequently receive remittances. The positive impact of secondary and tertiary education, respectively, detects that migration selects positively on education. Households in rural areas are less likely to receive the inflows. The key instruments, "Remittances in the community in 1999" and its interaction with the proportion of household members with secondary and tertiary education, respectively, are significant at the 0.1 percent level. This suggests that the instruments provide strong support for identification. A higher incidence of prior remittances in the community increases the likelihood of remittance receipt. This effect vanishes, however, with the educational level.

A range of Wu-Hausman tests confirm the necessity to identify causal effects: remittances are highly correlated with the error term in each expenditure category (see Appendix). Performed Sargan tests do not reject that the error term is uncorrelated with the instruments which suggests that our instruments are valid. Moreover, the first stage

Table 3 First stage estimates of the IVs

\begin{tabular}{|c|c|c|c|}
\hline \multicolumn{4}{|l|}{ Dependent variable: Remittance receipt } \\
\hline Gender of the household head & Both & Male & Female \\
\hline \multirow[t]{2}{*}{ Log(per-capita expenditures) } & $0.035^{* * *}$ & $0.073^{* * *}$ & $0.071^{* * *}$ \\
\hline & $(0.004)$ & $(0.011)$ & $(0.011)$ \\
\hline \multirow[t]{2}{*}{ Log(household size) } & $0.050^{* * *}$ & $0.098^{* * *}$ & $0.102^{* * *}$ \\
\hline & $(0.007)$ & $(0.018)$ & $(0.018)$ \\
\hline \multirow[t]{2}{*}{ Prop. of children $<15$} & -0.032 & $0.119^{*}$ & 0.087 \\
\hline & $(0.017)$ & $(0.050)$ & $(0.044)$ \\
\hline \multirow[t]{2}{*}{ Prop. of adults $>=15$ with prim. educ. } & -0.012 & 0.018 & 0.002 \\
\hline & $(0.015)$ & $(0.034)$ & $(0.033)$ \\
\hline \multirow[t]{2}{*}{ Prop. of adults $>=15$ with sec. educ. } & $0.064^{* * *}$ & $0.110^{*}$ & -0.023 \\
\hline & $(0.019)$ & $(0.047)$ & $(0.047)$ \\
\hline \multirow[t]{2}{*}{ Prop. of adults $>=15$ with ter. educ. } & $0.090^{* * *}$ & 0.089 & 0.052 \\
\hline & $(0.022)$ & $(0.053)$ & $(0.056)$ \\
\hline \multirow[t]{2}{*}{ Rural area } & $-0.033^{* * *}$ & -0.006 & -0.039 \\
\hline & $(0.007)$ & $(0.020)$ & $(0.020)$ \\
\hline \multirow[t]{2}{*}{ Remittances in the community in 1999} & $2.069^{* * *}$ & $2.080^{* * *}$ & $1.721^{* * *}$ \\
\hline & $(0.106)$ & $(0.285)$ & $(0.239)$ \\
\hline \multirow[t]{2}{*}{-sec. educ. } & $-0.900^{* * *}$ & -0.950 & $1.342^{*}$ \\
\hline & $(0.227)$ & $(0.596)$ & $(0.571)$ \\
\hline \multirow[t]{2}{*}{-ter. educ. } & $-2.031^{* * *}$ & $-1.426^{*}$ & -0.922 \\
\hline & $(0.256)$ & $(0.642)$ & $(0.713)$ \\
\hline \multirow[t]{2}{*}{ Constant } & $-0.183^{* * *}$ & $-0.540^{* * *}$ & $-0.460^{* * *}$ \\
\hline & $(0.037)$ & $(0.089)$ & $(0.091)$ \\
\hline R-squared & 0.057 & 0.094 & 0.113 \\
\hline Observations & 12488 & 2211 & 2210 \\
\hline F-statistic of the instruments $F(3, N-k-1)$ & 165 & 23 & 42 \\
\hline
\end{tabular}

Note: Bootstrapped standard errors in parentheses (with 500 reps.): ${ }^{*}$ significant at $5 \% ;{ }^{* *}$ at $1 \% ;{ }^{* * *}$ at $0.1 \%$. 
F-statistic of the instruments (F-test $=165)$ is well above the critical values outlined by Stock and Yogo (2002) to detect weak instruments.

To test, whether the assumption of normally distributed errors (probit model) is consistent with the data, Figure 1 presents the estimates from both the probit and the KS method as well as the 95 percent confidence interval of the probit estimate. The more sophisticated semiparametric method makes no distributional assumptions, and is therefore able to reveal a distribution structure that may differ from the Gaussian normal distribution. The left graph presents the estimates for the category health. The KS estimate hardly ever lies within the 95 percent confidence interval of the probit estimate. The assumption of normally distributed error terms has to be rejected. In the right graph, the estimates differ only little, but significantly, for some probability values. It seems crucial to apply both the consistent semiparametric and the commonly used and easy to implement SY method to get consistent estimates, and to analyze how much the results from both methods differ.

The results of the nonlinear SUR estimations of the equation system are presented in the Appendix. To account for the additional variability introduced by the two-step nature of the estimation process and by estimating the IV, the estimates are bootstrapped (with 500 replications). Most household characteristics are highly significant which is also true for the IV of remittance receipt. From the equation system (6) counterfactual average budget shares can be predicted which are shown in Table 4 . These are the average budget shares of hypothetical households with mean $X_{j}$ that differ in no characteristic but in the probability of remittance receipt. The method allows comparing a remittancereceiving household with its non-receiving counterpart, and the difference is the impact of remittance receipt, the average treatment effect (ATE).

The effects are large, and the results are robust with respect to the estimation method applied; both methods yield almost identical results. Remittance receiving households spend 8 percentage points more on health, 4-5 percentage points more on education, and 28 percentage points more on housing when compared to what they would spend without the transfers. Food expenses decrease by 22 percentage points. These results are in line with findings from Adams and Cuecuecha (2010): remittance receiving households spend more at the margin on housing, education, and health in Guatemala. Although the authors evaluate the effects on the marginal budget shares based on a different modeling approach, they find a similar relative increase of 80- 200 percent. Using Mexican data,
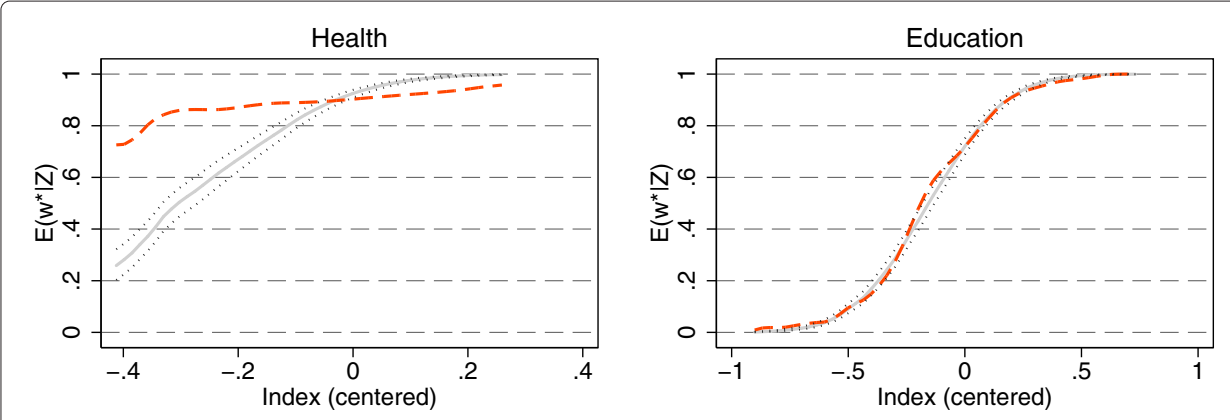

Solid line: Probit estimate

Dashed line: KS estimate

Dotted lines: 95\% confidence interval (Probit estimate)

Figure 1 Distribution of KS and probit estimate. 
Table 4 Average budget shares

\begin{tabular}{|c|c|c|c|c|c|c|c|c|}
\hline & \multicolumn{4}{|c|}{ Parametric SY method } & \multicolumn{4}{|c|}{ Semiparametric KS method } \\
\hline & Food & Housing & Health & Education & Food & Housing & Health & Education \\
\hline NR & $53.52 \%$ & $13.70 \%$ & $1.88 \%$ & $3.80 \%$ & $53.54 \%$ & $13.70 \%$ & $1.93 \%$ & $3.72 \%$ \\
\hline $\mathrm{RR}$ & $31.16 \%$ & $41.33 \%$ & $9.97 \%$ & $8.18 \%$ & $31.15 \%$ & $41.32 \%$ & $9.81 \%$ & $8.43 \%$ \\
\hline ATE & $-22.36 \%$ & $27.63 \%$ & $8.09 \%$ & $4.38 \%$ & $-22.39 \%$ & $27.63 \%$ & $7.87 \%$ & $4.71 \%$ \\
\hline
\end{tabular}

Notes: All average budget shares are estimated for household with mean values. NR = non remittance receiving households, RR $=$ remittance receiving households, ATE $=$ average treatment effect.

Amuedo-Dorantes and Pozo (2011) find that international remittances raise health care expenditures. Calero et al. (2009) who use the same data as this study also detect a positive impact of remittances on schooling in Ecuador. The increase in housing expenses is in line with the findings of Soruco et al. (2008) who analyze remittances in Ecuador; after the loans for transportation costs are repaid, the first investment financed by remittances is usually directed towards housing. Taylor and Mora (2006) as well as Zarate-Hoyos (2004) provide evidence that remittances result in lower expenditures on food, and substantially higher expenditures on housing.

\subsection{The impact of gender}

We match female and male headed households to make both household types comparable. All explanatory variables used in the estimations are listed in the Appendix. A t-test is performed to analyze whether significant differences in means are prevalent between the treated and control group. While the hypothesis of "no difference in means" can be rejected for most variables at the 5 percent level in the full sample, it cannot be rejected in the matched subsample. However, the matching procedure reduces the number of observations considerably. Female headed households are very different from their male counterparts, and 300 of them were in a stratum without any control observation. Consequently, they were excluded which leaves 2210 female headed households for which a similar male headed household can be identified.

Table 3 and the Appendix present the first-stage results as well as tests of the instruments, respectively, for both household types. The gender-specific first-stage results are rather similar. Remittance receipt is more likely the higher the incidence of prior remittances within the community is. Yet, while this effect is decreasing with the educational level in male headed households, it is even increasing with the proportion of household members with secondary education in female headed households. Sargan-tests as well as F-tests of the instruments suggest that the instruments are valid. Wu-Hausman tests indicate that at least in the categories "housing" and "education" remittances are highly endogenous for both household types. When estimating a system of equations, remittance receipt should either enter each equation as a variable, or should be instrumented in each equation, which is done here.

To determine, whether the distributional assumptions made by the probit model are consistent with the data, the participation equations are estimated by both methods. Similar to the findings from the full sample, Figure 2 reveals that the assumptions are partly violated. In the category "education", the KS estimate lies within the 95 percent confidence interval of the probit estimate. In contrast, the probit estimate is significantly lower for low probability values in the category "health". 


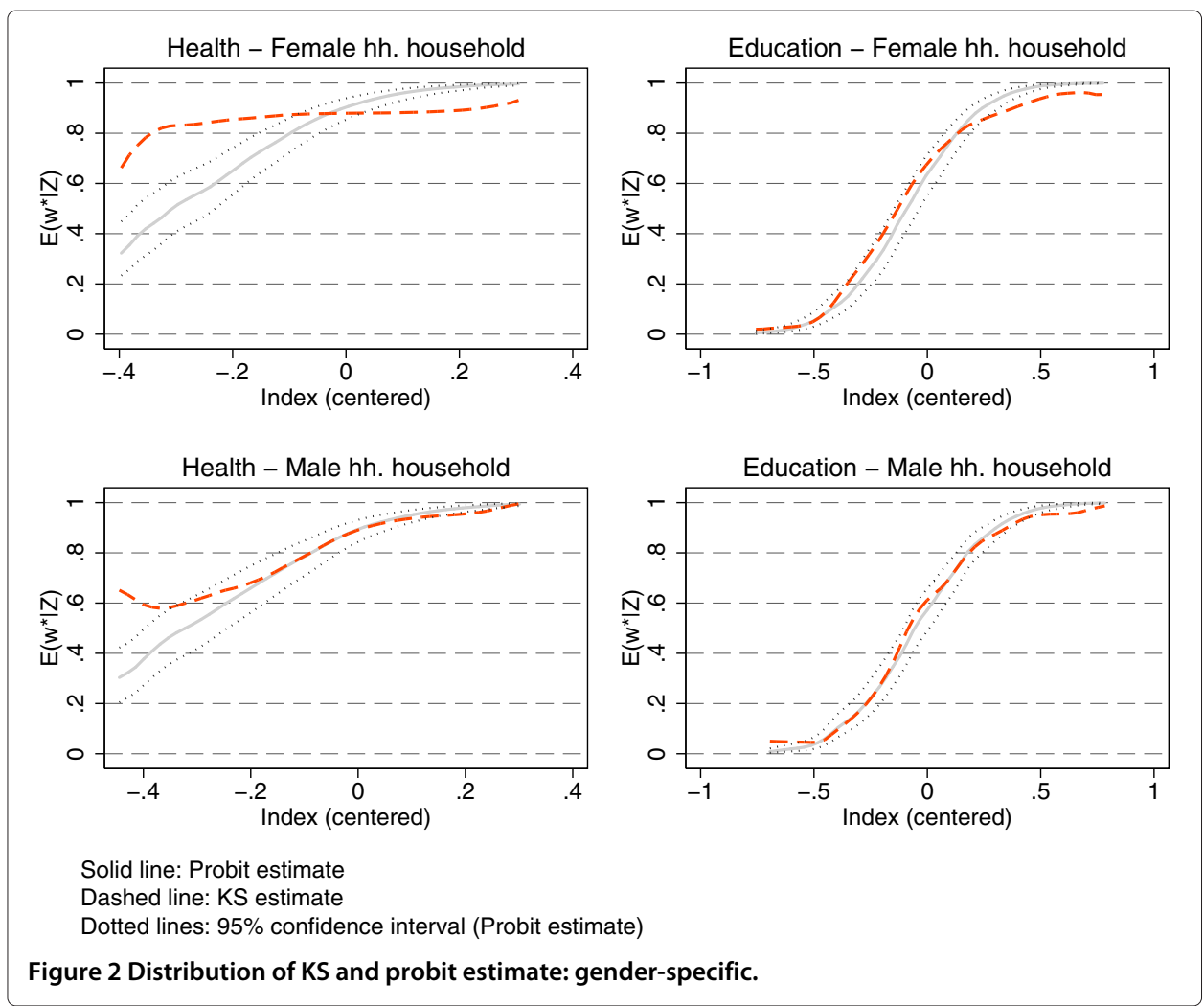

The results from the iterative nonlinear SUR estimations are shown in the Appendix. The remittance instrument is significant and has the same sign for both genders. Table 5 presents the estimated average budget shares. Although the distributional assumption of the SY method is violated in the category health, both methods yield very similar results. Without remittances both household types show a rather similar expenditure behavior. Yet, female headed households spend slightly more on food, education, and health than their male counterparts. The impact of remittances is also not substantially different. Remittances decrease expenditures on food by 32 percentage points, while those on housing, health, and education increase by 32,8 , and 4 percentage points, respectively, in female headed households. In male headed households, remittances results in a

Table 5 Average budget shares: gender-specific

\begin{tabular}{|c|c|c|c|c|c|c|c|c|}
\hline & \multicolumn{4}{|c|}{ Parametric SY method } & \multicolumn{4}{|c|}{ Semiparametric KS method } \\
\hline & Food & Housing & Health & Education & Food & Housing & Health & Education \\
\hline \multicolumn{9}{|c|}{ Female headed households } \\
\hline NR & $60.93 \%$ & $12.43 \%$ & $1.71 \%$ & $3.51 \%$ & $61.02 \%$ & $12.43 \%$ & $1.51 \%$ & $3.82 \%$ \\
\hline $\mathrm{RR}$ & $28.64 \%$ & $43.95 \%$ & $9.30 \%$ & $7.95 \%$ & $28.34 \%$ & $43.94 \%$ & $10.36 \%$ & $6.99 \%$ \\
\hline ATE & $-32.28 \%$ & $31.53 \%$ & $7.59 \%$ & $4.44 \%$ & $-32.68 \%$ & $31.51 \%$ & $8.85 \%$ & $3.16 \%$ \\
\hline \multicolumn{9}{|c|}{ Male headed households } \\
\hline NR & $52.47 \%$ & $11.23 \%$ & $1.13 \%$ & $3.34 \%$ & $52.28 \%$ & $11.22 \%$ & $1.41 \%$ & $3.08 \%$ \\
\hline $\mathrm{RR}$ & $43.92 \%$ & $39.90 \%$ & $10.88 \%$ & $5.41 \%$ & $44.45 \%$ & $39.91 \%$ & $9.99 \%$ & $6.41 \%$ \\
\hline ATE & $-8.55 \%$ & $28.67 \%$ & $9.75 \%$ & $2.07 \%$ & $-7.83 \%$ & $28.69 \%$ & $8.58 \%$ & $3.33 \%$ \\
\hline
\end{tabular}

Notes: All average budget shares are estimated for household with mean values. NR $=$ non remittance receiving households, RR $=$ remittance receiving households, ATE = average treatment effect. 
9 percentage points lower food share, and housing, health, and education increase by 29 , 10 , and 2 percentage points, respectively.

In a third step, the impact of the gender of the remitter and the receiver is analyzed using a subsample of 616 remittance-receiving households. Additional covariates are "Male migrant" and "Male receiver" which are both defined as proportional values. The former is the proportion of male migrants, whereas the latter is the proportion of male receivers. ${ }^{11}$ The validity of the distributional assumption made using the SY method cannot be rejected, and hence only the SY method is performed in the following (see Appendix). Covariates such as total per-capita expenditures and household size are with the same sign as in the previous estimation, but overall less significant due to the much smaller sample size (see Table 6). If the remitter is female, expenditures on education increase by one percentage point (weakly significant). Similarly, the female sex of the receiver results in a significant increase in education expenses by 2 percentage points.

\section{Conclusions}

Migration and remittances take an important position in the economy of Ecuador which considerably affects the remaining households and the dynamics of the whole economy. The effect on development mainly depends on the use of the international transfers, and the literature suggests gender-specific preferences in the use of income. This study analyzes the impact of remittances and gender on household expenditure patterns by

Table 6 Full estimates for the sample selection model: the migrant

\begin{tabular}{|c|c|c|c|c|}
\hline & & Parame & method & \\
\hline & Food & Housing & Health & Education \\
\hline Log(per-capita expenditures) & $-0.123^{* * *}$ & $0.054^{* * *}$ & $-0.015^{* * *}$ & $-0.028^{* * *}$ \\
\hline & $(0.011)$ & $(0.014)$ & $(0.003)$ & $(0.010)$ \\
\hline Log(household size) & $-0.130^{* * *}$ & $0.042^{* *}$ & 0.002 & 0.010 \\
\hline & $(0.019)$ & $(0.017)$ & $(0.007)$ & $(0.029)$ \\
\hline Prop. of children $<15$ & 0.064 & -0.028 & $-0.023^{*}$ & 0.037 \\
\hline & $(0.040)$ & $(0.036)$ & $(0.012)$ & $(0.040)$ \\
\hline Prop. of adults $>=15$ with prim. educ. & -0.059 & 0.040 & $0.037^{* * *}$ & -0.007 \\
\hline & $(0.057)$ & $(0.040)$ & $(0.013)$ & $(0.015)$ \\
\hline Prop. of adults $>=15$ with sec. educ. & -0.089 & 0.007 & $0.025^{*}$ & -0.005 \\
\hline & $(0.058)$ & $(0.039)$ & $(0.014)$ & $(0.015)$ \\
\hline Prop. of adults $>=15$ with ter. educ. & $-0.118^{*}$ & -0.058 & $0.024^{*}$ & $0.083^{* * *}$ \\
\hline & $(0.061)$ & $(0.045)$ & $(0.013)$ & $(0.029)$ \\
\hline Rural area & $-0.131^{* * *}$ & $0.060^{* * *}$ & -0.001 & -0.004 \\
\hline & $(0.019)$ & $(0.019)$ & $(0.006)$ & $(0.006)$ \\
\hline Male receiver & -0.010 & -0.026 & -0.001 & $-0.020^{* *}$ \\
\hline & $(0.022)$ & $(0.020)$ & $(0.009)$ & $(0.008)$ \\
\hline Male migrant & -0.002 & -0.002 & 0.004 & $-0.014^{*}$ \\
\hline & $(0.018)$ & $(0.017)$ & $(0.007)$ & $(0.008)$ \\
\hline Selection term I & & & 0.072 & 0.034 \\
\hline & & & $(0.051)$ & $(0.052)$ \\
\hline Constant & $1.681^{* * *}$ & $-0.270^{* *}$ & $0.115^{* * *}$ & $0.236^{*}$ \\
\hline & $(0.103)$ & $(0.120)$ & $(0.032)$ & $(0.136)$ \\
\hline R-squared & 0.245 & 0.070 & 0.273 & 0.463 \\
\hline $\mathrm{N}$ & 616 & 616 & 616 & 616 \\
\hline
\end{tabular}


employing both parametric and semiparametric techniques. The results are very robust with respect to the estimation method applied and illustrate that remittance receipt enhances expenditures on education and health. The effects are large. Remittances might hence result in a stronger human capital accumulation with positive external effects for the rest of the economy as well. Moreover, remittances increase expenditures on housing. While for the economy this is consumption, from the part of the migrant it is an investment and results in future savings. In addition, investment in housing may spur the local construction sector and has a positive impact on families' health. In order to evaluate the overall impact on development, a well-specified growth model has to be employed which could be a promising approach for future research.

The literature on remittances suggests that including a gender perspective is crucial. Our findings, however, contradict this perception: the gender-specific impacts concerning expenditure patterns in Ecuador are rather small. In the absence of remittances, female household heads spend slightly more on food, education, and housing than their male counterparts. In consequence, the family well-being and human-capital formation might improve with a female head of the households, but the effects are small. The impact of remittance receipt is similar for both genders: the inflows are associated with higher expenditures on education, health, and housing and smaller food expenses. Only the reduction in food expenses is much stronger for female headed households. In addition, the evidence suggests that the sex of the remitter and the receiver affects the expenditure behavior, at which the impact of the sex of the receiver seems to be more important. Both a female migrant and a female receiver increase expenditures on education. Due to data restrictions these aspects are rather weak and not estimated further, and more research seems to be warranted that addresses this question in particular.

\section{Appendix}

The following appendix provides some additional tests, tables and figures of the previous estimations in section five. A range of Wu-Hausman tests to confirm the necessity to use IVs and Sargan tests that indicate that this approach is valid are provided in Table 7. Table 8 presents all explanatory variables disaggregated by gender as well

Table 7 Tests of the IVs

\begin{tabular}{lllll}
\hline & Food & Housing & Education & Health \\
\hline All households & & & & \\
Wu-Hausman F(1, N) & 42.691 & 121.622 & 67.865 & 14.400 \\
$\quad$ p-value & 0.000 & 0.000 & 0.000 & 0.000 \\
Sargan score $\chi^{2}(2)$ & 4.052 & 0.557 & 4.904 & 4.087 \\
$\quad$ p-value & 0.132 & 0.757 & 0.086 & 0.130 \\
Female headed households & & & & \\
Wu-Hausman F(1, N) & 21.663 & 48.129 & 20.729 & 3.322 \\
$\quad$-value & 0.000 & 0.000 & 0.000 & 0.068 \\
Sargan score $\chi^{2}(2)$ & 1.524 & 1.789 & 3.439 & 0.524 \\
$\quad$ p-value & 0.467 & 0.409 & 0.179 & 0.770 \\
Male headed households & & & & 0.077 \\
Wu-Hausman $\mathrm{F}(1, \mathrm{~N})$ & 2.037 & 11.991 & 7.540 & 0.781 \\
$\quad$-value & 0.154 & 0.001 & 0.006 & 2.221 \\
Sargan score $\chi^{2}(2)$ & 0.013 & 1.802 & 3.562 & 0.329 \\
$\quad$ p-value & 0.994 & 0.406 & 0.168 & \\
\hline
\end{tabular}


as t-tests that analyze indicate whether significant differences in means are prevalent between male and female headed households before and after matching. Table 9 and 10 show the full estimation results for the full sample and gender subsamples, respectively. Figure 3 presents the first step estimates from both the probit and the KS method for the migrant subsample.

Table 8 Balancing

\begin{tabular}{|c|c|c|c|c|}
\hline \multirow[b]{2}{*}{ Gender of the household head } & \multicolumn{2}{|c|}{ Full sample } & \multicolumn{2}{|c|}{ Matched sample } \\
\hline & Male & Female & Male & Female \\
\hline Log(per-capita expenditures) & 6.753 & $6.831^{*}$ & 6.863 & 6.815 \\
\hline Log(household size) & 1.322 & $1.037^{*}$ & 1.064 & 1.064 \\
\hline Prop. of children $<15$ & 0.287 & $0.261^{*}$ & 0.207 & 0.218 \\
\hline Prop. of adults $>=15$ with prim. educ. & 0.454 & $0.433^{*}$ & 0.427 & 0.449 \\
\hline Prop. of adults $>=15$ with sec. educ. & 0.294 & $0.271^{*}$ & 0.275 & 0.262 \\
\hline Prop. of adults $>=15$ with ter. educ. & 0.162 & 0.162 & 0.173 & 0.156 \\
\hline Rural area & 1.450 & $1.365^{*}$ & 1.367 & 1.367 \\
\hline Remittance receipt (\%) & 0.134 & $0.252^{*}$ & 0.207 & 0.207 \\
\hline
\end{tabular}

Note: The difference between male and female headed households is significant * at $5 \%$

Table 9 Full estimates for the sample selection models

\begin{tabular}{|c|c|c|c|c|c|c|c|c|}
\hline & \multicolumn{4}{|c|}{ Parametric SY method } & \multicolumn{4}{|c|}{ Semiparametric KS method } \\
\hline & Food & Housing & Health & Education & Food & Housing & Health & Education \\
\hline \multirow[t]{2}{*}{$\log (\exp )$} & $-0.080^{* * *}$ & $0.010^{* *}$ & $-0.013^{* * *}$ & $-0.029^{* * *}$ & $-0.080^{* * *}$ & $0.010^{* *}$ & $-0.022^{*}$ & $-0.029^{* * *}$ \\
\hline & $(0.004)$ & $(0.003)$ & $(0.001)$ & $(0.004)$ & $(0.004)$ & $(0.003)$ & $(0.010)$ & $(0.004)$ \\
\hline \multirow[t]{2}{*}{$\log (\mathrm{hh})$} & $-0.108^{* * *}$ & $0.014^{* * *}$ & $-0.011^{* * *}$ & 0.000 & $-0.108^{* * *}$ & $0.014^{* * *}$ & $-0.007^{*}$ & -0.001 \\
\hline & $(0.006)$ & $(0.004)$ & $(0.003)$ & $(0.007)$ & $(0.006)$ & $(0.004)$ & $(0.003)$ & $(0.007)$ \\
\hline \multirow[t]{2}{*}{ Child. } & $0.091^{* * *}$ & $-0.062^{* * *}$ & $-0.025^{* * *}$ & -0.018 & $0.090^{* * *}$ & $-0.062^{* * *}$ & $-0.024^{* * *}$ & $-0.021^{*}$ \\
\hline & $(0.011)$ & $(0.008)$ & $(0.003)$ & $(0.009)$ & $(0.011)$ & $(0.008)$ & $(0.004)$ & $(0.009)$ \\
\hline \multirow[t]{2}{*}{ Prim. } & $-0.119^{* * *}$ & $0.039^{* * *}$ & $0.009^{*}$ & -0.004 & $-0.116^{* * *}$ & $0.039^{* * *}$ & $0.013^{* * *}$ & 0.008 \\
\hline & $(0.011)$ & $(0.007)$ & $(0.004)$ & $(0.008)$ & $(0.011)$ & $(0.007)$ & $(0.003)$ & $(0.007)$ \\
\hline \multirow[t]{2}{*}{ Sec. } & $-0.203^{* * *}$ & $0.045^{* * *}$ & 0.004 & 0.008 & $-0.200^{* * *}$ & $0.045^{* * *}$ & 0.006 & $0.019^{*}$ \\
\hline & $(0.012)$ & $(0.008)$ & (0.004) & $(0.009)$ & $(0.012)$ & $(0.008)$ & $(0.005)$ & $(0.008)$ \\
\hline \multirow[t]{2}{*}{ Ter. } & $-0.320^{* * *}$ & $0.088^{* * *}$ & $0.013^{* *}$ & $0.057^{* * *}$ & $-0.317^{* * *}$ & $0.088^{* * *}$ & $0.018^{* * *}$ & $0.066^{* * *}$ \\
\hline & $(0.012)$ & $(0.009)$ & $(0.005)$ & $(0.011)$ & $(0.012)$ & $(0.009)$ & $(0.004)$ & $(0.010)$ \\
\hline \multirow[t]{2}{*}{ Rural } & $-0.044^{* * *}$ & $0.011^{* *}$ & $0.009^{* * *}$ & $-0.005^{*}$ & $-0.044^{* * *}$ & $0.011^{* *}$ & $0.008^{* * *}$ & $-0.005^{*}$ \\
\hline & $(0.006)$ & $(0.004)$ & $(0.002)$ & $(0.002)$ & $(0.006)$ & $(0.004)$ & $(0.002)$ & $(0.002)$ \\
\hline \multirow[t]{2}{*}{ IV } & $-0.224^{* * *}$ & $0.276^{* * *}$ & $0.089^{* * *}$ & $0.066^{* * *}$ & $-0.224^{* * *}$ & $0.276^{* * *}$ & $0.087^{* * *}$ & $0.071^{* * *}$ \\
\hline & $(0.032)$ & $(0.025)$ & $(0.013)$ & $(0.012)$ & $(0.032)$ & $(0.025)$ & $(0.013)$ & $(0.012)$ \\
\hline \multirow[t]{2}{*}{ SI } & & & -0.006 & 0.006 & & & -0.092 & -0.001 \\
\hline & & & $(0.012)$ & $(0.010)$ & & & $(0.424)$ & $(0.010)$ \\
\hline \multirow[t]{2}{*}{ SII } & & & & & & & -0.488 & \\
\hline & & & & & & & $(1.152)$ & \\
\hline \multirow[t]{2}{*}{ S III } & & & & & & & 0.956 & \\
\hline & & & & & & & $(1.464)$ & \\
\hline \multirow[t]{2}{*}{ C } & $1.416^{* * *}$ & 0.011 & $0.112^{* * *}$ & $0.253^{* * *}$ & $1.416^{* * *}$ & 0.011 & 0.191 & $0.250^{* * *}$ \\
\hline & $(0.032)$ & $(0.026)$ & $(0.012)$ & $(0.034)$ & $(0.033)$ & $(0.026)$ & $(0.119)$ & $(0.033)$ \\
\hline R2 & 0.259 & 0.054 & 0.209 & 0.396 & 0.259 & 0.054 & 0.209 & 0.396 \\
\hline$N$ & 12488 & 12488 & 12488 & 12488 & 12488 & 12488 & 12488 & 12488 \\
\hline
\end{tabular}

Notes: For a description of the explanatory variables see Table 8. Bootstrapped standard errors in parentheses (with 500 reps.):

* significant at $5 \%$; ${ }^{* *}$ significant at $1 \%$; ${ }^{* * *}$ significant at $0.1 \%$. 
Table 10 Full estimates for the sample selection models: gender-specific

\begin{tabular}{|c|c|c|c|c|c|c|c|c|}
\hline & \multicolumn{4}{|c|}{ Parametric SY method } & \multicolumn{4}{|c|}{ Semiparametric KS method } \\
\hline & Food & Housing & Health & Education & Food & Housing & Health & Education \\
\hline \multicolumn{9}{|c|}{ Female headed households } \\
\hline \multirow[t]{2}{*}{$\log (\exp )$} & $-0.024^{*}$ & $-0.023^{* *}$ & $-0.020^{* * *}$ & $-0.036^{* * *}$ & $-0.022^{*}$ & $-0.022^{* *}$ & $-0.057^{* * *}$ & $-0.035^{* * *}$ \\
\hline & $(0.010)$ & $(0.008)$ & $(0.003)$ & $(0.011)$ & $(0.010)$ & $(0.008)$ & $(0.017)$ & $(0.009)$ \\
\hline \multirow[t]{2}{*}{$\log (\mathrm{hh})$} & $-0.070^{* * *}$ & $-0.041^{* * *}$ & $-0.021^{* *}$ & -0.019 & $-0.069^{* * *}$ & $-0.041^{* * *}$ & $-0.015^{* *}$ & $-0.028^{*}$ \\
\hline & $(0.012)$ & $(0.010)$ & $(0.007)$ & $(0.020)$ & $(0.012)$ & $(0.010)$ & $(0.005)$ & $(0.014)$ \\
\hline \multirow[t]{2}{*}{ Child. } & $0.121^{* * *}$ & $-0.065^{* * *}$ & $-0.027^{* * *}$ & 0.010 & $0.123^{* * *}$ & $-0.065^{* * *}$ & $-0.030^{* * *}$ & 0.020 \\
\hline & $(0.026)$ & $(0.019)$ & $(0.008)$ & $(0.023)$ & $(0.026)$ & $(0.019)$ & $(0.008)$ & $(0.014)$ \\
\hline \multirow[t]{2}{*}{ Prim. } & $-0.119^{* * *}$ & $0.060^{* * *}$ & $0.016^{*}$ & 0.007 & $-0.119^{* * *}$ & $0.061^{* * *}$ & $0.017^{* *}$ & 0.013 \\
\hline & $(0.021)$ & $(0.014)$ & $(0.007)$ & $(0.013)$ & $(0.021)$ & $(0.014)$ & $(0.006)$ & $(0.012)$ \\
\hline \multirow[t]{2}{*}{ Sec. } & $-0.217^{* * *}$ & $0.088^{* * *}$ & 0.010 & 0.016 & $-0.218^{* * *}$ & $0.087^{* * *}$ & 0.011 & 0.023 \\
\hline & $(0.025)$ & $(0.017)$ & (0.008) & $(0.013)$ & $(0.025)$ & $(0.017)$ & $(0.008)$ & $(0.013)$ \\
\hline \multirow[t]{2}{*}{ Ter. } & $-0.386^{* * *}$ & $0.139^{* * *}$ & $0.021^{*}$ & $0.085^{* * *}$ & $-0.386^{* * *}$ & $0.139^{* * *}$ & $0.025^{* *}$ & $0.111^{* * *}$ \\
\hline & $(0.026)$ & $(0.018)$ & (0.009) & $(0.018)$ & $(0.026)$ & $(0.018)$ & $(0.008)$ & $(0.016)$ \\
\hline \multirow[t]{2}{*}{ Rural } & -0.023 & -0.006 & 0.006 & -0.007 & -0.022 & -0.006 & 0.008 & 0.004 \\
\hline & $(0.013)$ & $(0.010)$ & $(0.004)$ & $(0.005)$ & $(0.013)$ & (0.010) & $(0.004)$ & $(0.007)$ \\
\hline \multirow[t]{2}{*}{ IV } & $-0.323^{* * *}$ & $0.315^{* * *}$ & $0.087^{* * *}$ & $0.076^{* *}$ & $-0.327^{* * *}$ & $0.315^{* * *}$ & $0.101^{* * *}$ & $0.054^{*}$ \\
\hline & $(0.054)$ & $(0.043)$ & $(0.020)$ & $(0.028)$ & $(0.054)$ & $(0.043)$ & $(0.021)$ & $(0.027)$ \\
\hline \multirow[t]{2}{*}{ SI } & & & -0.005 & 0.017 & & & -1.772 & -0.004 \\
\hline & & & $(0.022)$ & $(0.024)$ & & & $(1.186)$ & $(0.023)$ \\
\hline \multirow[t]{2}{*}{ SII } & & & & & & & 3.233 & \\
\hline & & & & & & & (3.967) & \\
\hline \multirow[t]{2}{*}{ S III } & & & & & & & -3.257 & \\
\hline & & & & & & & $(5.265)$ & \\
\hline R2 & 0.259 & 0.084 & 0.214 & 0.398 & 0.259 & 0.084 & 0.216 & 0.406 \\
\hline N & 2210 & 2210 & 2210 & 2210 & 2210 & 2210 & 2210 & 2210 \\
\hline \multicolumn{9}{|c|}{ Male headed households } \\
\hline \multirow[t]{2}{*}{$\log (\exp )$} & $-0.061^{* * *}$ & $-0.017^{*}$ & $-0.016^{* * *}$ & $0.033^{* * *}$ & $-0.061^{* * *}$ & $-0.017^{*}$ & $-0.012^{* *}$ & $-0.033^{* * *}$ \\
\hline & $(0.010)$ & $(0.008)$ & $(0.004)$ & $(0.009)$ & $(0.010)$ & $(0.008)$ & $(0.004)$ & $(0.010)$ \\
\hline \multirow[t]{2}{*}{$\log (\mathrm{hh})$} & $-0.073^{* * *}$ & 0.002 & $-0.015^{*}$ & -0.003 & $-0.073^{* * *}$ & 0.002 & -0.007 & 0.009 \\
\hline & $(0.015)$ & $(0.011)$ & $(0.008)$ & $(0.015)$ & $(0.015)$ & $(0.011)$ & $(0.009)$ & $(0.018)$ \\
\hline \multirow[t]{2}{*}{ Child. } & $0.078^{*}$ & $-0.135^{* * *}$ & $-0.044^{* * *}$ & -0.030 & $0.079^{*}$ & $-0.135^{* * *}$ & $-0.042^{* * *}$ & 0.001 \\
\hline & $(0.031)$ & $(0.024)$ & $(0.010)$ & $(0.032)$ & $(0.031)$ & $(0.024)$ & $(0.010)$ & $(0.027)$ \\
\hline \multirow[t]{2}{*}{ Prim. } & $-0.136^{* * *}$ & 0.018 & 0.008 & -0.014 & $-0.135^{* * *}$ & 0.018 & $0.018^{*}$ & -0.014 \\
\hline & $(0.023)$ & $(0.014)$ & $(0.009)$ & $(0.011)$ & $(0.023)$ & $(0.014)$ & $(0.007)$ & $(0.011)$ \\
\hline Sec. & $-0.214^{* * *}$ & 0.023 & 0.002 & 0.012 & $-0.212^{* * *}$ & 0.023 & 0.015 & 0.018 \\
\hline & $(0.027)$ & $(0.017)$ & $(0.011)$ & $(0.012)$ & $(0.027)$ & $(0.017)$ & $(0.008)$ & $(0.011)$ \\
\hline Ter. & $-0.347^{* * *}$ & $0.076^{* * *}$ & 0.012 & $0.043^{* *}$ & $-0.345^{* * *}$ & $0.076^{* * *}$ & $0.023^{* *}$ & $0.056^{* * *}$ \\
\hline & $(0.029)$ & $(0.021)$ & $(0.012)$ & $(0.014)$ & $(0.029)$ & $(0.021)$ & (0.009) & $(0.015)$ \\
\hline Rural & 0.011 & $-0.021^{*}$ & $0.012^{*}$ & $-0.023^{* * *}$ & 0.012 & $-0.021^{*}$ & 0.009 & $-0.024^{* * *}$ \\
\hline & $(0.014)$ & $(0.009)$ & $(0.005)$ & $(0.005)$ & $(0.014)$ & $(0.009)$ & $(0.007)$ & $(0.005)$ \\
\hline IV & -0.086 & $0.287^{* * *}$ & $0.113^{* *}$ & 0.038 & -0.078 & $0.287^{* * *}$ & $0.099^{* *}$ & 0.061 \\
\hline & $(0.085)$ & $(0.068)$ & $(0.042)$ & $(0.040)$ & $(0.085)$ & $(0.068)$ & $(0.038)$ & $(0.053)$ \\
\hline SI & & & 0.000 & 0.004 & & & 0.011 & 0.038 \\
\hline & & & $(0.023)$ & $(0.023)$ & & & $(0.063)$ & $(0.023)$ \\
\hline S॥ & & & & & & & 0.052 & \\
\hline & & & & & & & $(0.051)$ & \\
\hline R2 & 0.258 & 0.059 & 0.203 & 0.383 & 0.258 & 0.059 & 0.207 & 0.386 \\
\hline$N$ & 2211 & 2211 & 2211 & 2211 & 2211 & 2211 & 2211 & 2211 \\
\hline
\end{tabular}

Notes: The regressions include a constant (not shown). For a description of the explanatory variables see Table 8. Bootstrapped standard errors in parentheses (with 500 reps.):

${ }^{*}$ significant at $5 \%$; ** significant at $1 \% ; * * *$ significant at $0.1 \%$. 


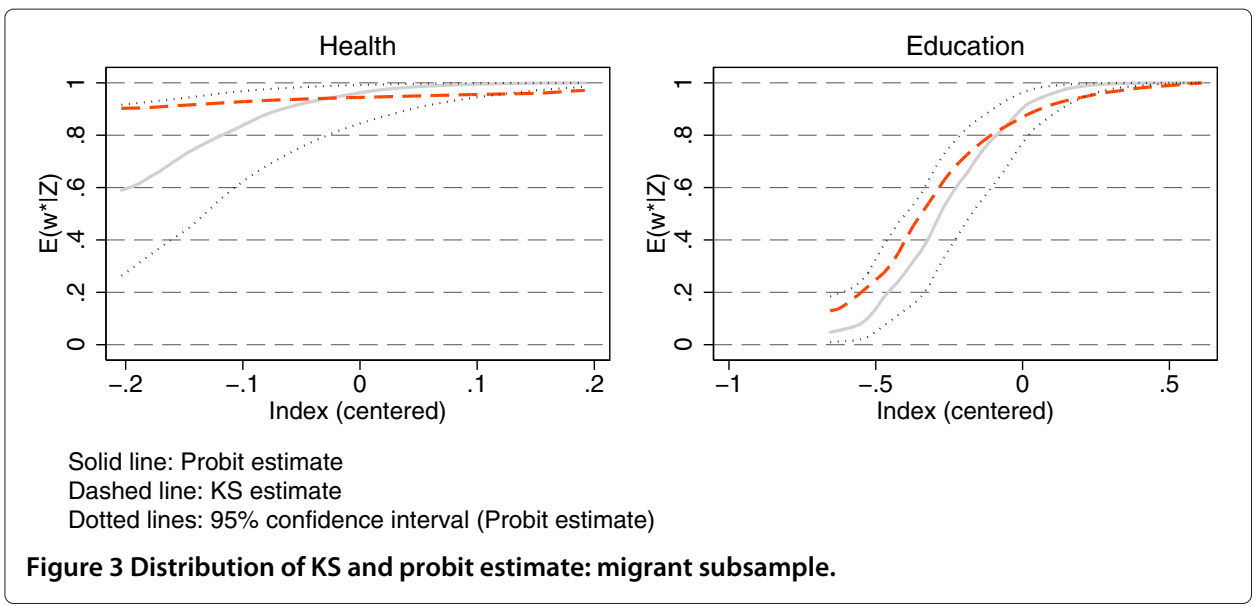

\section{Endnotes}

${ }^{1}$ In the subsequent empirical analysis, we construct an instrument on the basis of past remittance receipt within the community. Information from the previous round, ECV-4, are used which does not contain data from the Amazonas region.

${ }^{2}$ A household with an income of US\$ 300 which spends US\$ 50 on food, but receives costless food for US\$ 200 is counted as a household with an income of US\$ 500 spending US\$ 250 on food.

${ }^{3}$ Some destination countries like the United States have a strong demand for less qualified labor in the construction or agriculture sector, and therefore attract male migrants. In contrast, the need for workers in areas such as care, gastronomy or cleaning in countries like Spain favors female migration (Pfeiffer and Taylor (2008)).

${ }^{4}$ Female migrants are more often employed in the informal sector, and therefore receive less income than their male counterparts.

${ }^{5}$ If prices are available, the model can easily be extended to the widely applied Almost Ideal Demand System (AIDS) from Deaton and Muellbauer (1980).

${ }^{6}$ Following Taylor and Mora (2006), regional dummies as well as the variable "access to the house" are included. It indicates the main access to the house, ranging from "sea/ river" and "trail" to "highway". If households are poorly connected to markets that may explain, whether they spend on a specific good/ category. Yet, once they do spend, this should not affect the amount spent.

${ }^{7}$ An estimate for $F_{i}(\cdot)$ can be obtained nonparametrically, using the kernel method:

$F_{i}\left(\vartheta_{i j}\right)=\frac{\sum_{n=1}^{N} w_{i j}^{*} K\left[\left(\vartheta_{i j}-\vartheta_{i n}\right) / h\right]}{\sum_{n=1}^{N} K\left[\left(\vartheta_{i j}-\vartheta_{i n}\right) / h\right]}$, where $\vartheta_{i j}=\gamma_{i} Z_{j}$ and the bandwidth $h$ is a non-stochastic window. Estimates are obtained using the $\mathrm{R} n \mathrm{n}$ package developed by Hayfield and Racine (2008) that employs automatic (data-driven) bandwidth selection via cross validation. To ensure identification, the intercept is constrained to zero and the coefficient of one continuous regressor to one.

${ }^{8}$ Other power series that we consider include: (i) the index $\hat{\gamma}_{i} Z_{j}$ itself, and (ii) the normal $\operatorname{cdf} \Phi$. Estimates are robust to the exact form of the approximation.

${ }^{9}$ Due to the criterion of additivity, the variance-covariance matrix of error terms for a complete equation demand system will be singular. With the SY correction method, the 
error terms do not sum up to zero by construction. Consequently, the budget shares do only almost equal one. Nevertheless, this makes convergence difficult. The normal procedure is to delete one of the equations, here the miscellaneous category "other", from the system. As no censoring is present in the categories "food" and "housing", both enter the system as in equation (1).

${ }^{10}$ Note, that to control for the endogeneity of remittances and gender different methods are used. Matching is a procedure that eliminates endogeneity insofar as that afterwards both groups have exactly the same characteristics, i.e. observables. Thus, gender is not correlated anymore with the residual. However, matching does not eliminate any bias due to unobservables which is essential in the analysis of remittances. Yet, it would be very difficult to find a reasonable instrument for gender, and therefore matching is the chosen technique here.

${ }^{11}$ In 70 percent of all households, only one person receives the remittance, and 77 percent of all households have only one migrant. The results are robust to restricting the analysis to those observations.

\section{Competing interests}

The IZA Journal of Migration is committed to the IZA Guiding Principles of Research Integrity. The author declares that she observed these principles.

\section{Acknowledgements}

I would like to thank Michael Funke and Michael Paetz for helpful comments on an earlier draft of the paper. The usual disclaimer applies.

Responsible editor: Denis Fougère

Received: 10 October 2012 Accepted: 16 November 2012

Published: 10 January 2013

\section{References}

Adams RH, Cuecuecha A (2010) Remittances, household expenditure and investment in Guatemala. World Dev 38(11): 1626-1641

Amuedo-Dorantes C, Pozo S (2006) Migration, remittances, and male and female employment patterns. Am Econ Rev 96(2): 222-226

Amuedo-Dorantes, C, Pozo S (2011) New evidence on the role of remittances on healthcare expenditures by Mexican households. Rev Econ Household 9: 69-98

Blackwell M, lacus S, King G, Porro G (2009) CEM: Coarsened Exact Matching in Stata. Stata J 9(4): 524-546

Calero C, Bedi AS, Sparrow R (2009) Remittances, liquidity constraints and human capital investments in Ecuador. World Dev 37(6): 1143-1154

Chami R, Jahjah S, Fullenkamp C (2003) Are immigrant remittance flows a source of capital for development. IMF Working Papers 03/189, International Monetary Fund

Deaton AS, Muellbauer J (1980) An almost ideal demand system. Am Econ Rev 70(3): 312-326

Doss C (2006) The effects of intrahousehold property ownership on expenditure patterns in Ghana. J Afr Economies 15(1): 149-180

Duflo E, Udry C (2004) Intrahousehold resource allocation in Cote d'Ivoire: social norms, separate accounts and consumption choices. NBER Working Papers 10498, National Bureau of Economic Research, Inc.

Guzmán JC, Morrison AR, Sjöblom M (2008) The impact of remittances and gender on household expenditure patterns: evidence from Ghana In: Morrison AR, Schiff M, Sjöblom M (eds) The international migration of women. World Bank and Palgrave Macmillan, pp 125-152

Hanson GH, Woodruff C (2003) Emigration and educational attainment in Mexico. Unpublished paper

Hayfield T, Racine JS (2008) Nonparametric econometrics: the np package. J Stat Softw 27(5): 1-32

Heckman JJ (1979) Sample selection bias as a specification error. Econometrica 47(1): 153-161

Heien D, Wessells CR (1990) Demand systems estimation with microdata: A censored regression approach. J Bus Econ Stat 8(3): 365-371

Hildebrandt N, McKenzie DJ (2005) The effects of migration on child health in mexico. Economía 6(1): 257-289

Hoddinott J, Haddad L (1995) Does female income share influence household expenditures? Evidence from Cote d'Ivoire. Oxford Bull Econ Stat 57(1): 77-96

Klein RW, Spady RH (1993) An efficient semiparametric estimator for binary response models. Econometrica 61 (2): $387-421$

Leser CEV (1963) Forms of Engel functions. Econometrica 31(4): 694-703

López-Córdova E, Tokman A, Verhoogen EA (2005) Globalization, migration, and development: the role of Mexican migrant remittances. Economía 6(1): 217-256

Mason AD, King EM (2001) Engendering Development: Through Gender Equality in Rights, Resources, and Voice. World Bank and Oxford University Press, Washington, D.C. 
McKenzie D, Gibson J, Stillman S (2010) How important is selection? experimental vs. non-experimental measures of the income gains from migration. J Eur Econ Assoc 8(4): 913-945

McKenzie D, Rapoport H (2011) Can migration reduce educational attainment? Evidence from Mexico. J Popul Econ 24: $1331-1358$

Newey W (1999) Two step series estimation of sample selection models. Working papers 99-04, Massachusetts Institute of Technology (MIT), Department of Economics

Pew Hispanic Center and Benedixen and Associates (2003) Remittance recipients in Ecuador a market research study. Technical report, Inter- American Development Bank

Pfeiffer L, Taylor JE (2008) Gender and the impacts of international migration: evidence from rural Mexico In: Morrison AR, Schiff M, Sjöblom M (eds) The International Migration of Women. World Bank and Palgrave Macmillan, Washington, D.C. and New York, pp 9-124

Quisumbing AR, Maluccio JA (2000) Intrahousehold allocation and gender relations: New empirical evidence from four developing countries. FCND discussion papers 84 , International Food Policy Research Institute (IFPRI)

Sam AG, Zheng Y (2010) Semiparametric estimation of consumer demand systems with micro data. Am J Agric Econ 92(1): 246-257

Shonkwiler JS, Yen ST (1999) Two-step estimation of a censored system of equations. Am J Agric Econ 81 (4): 972-982

Soruco X, Piani G, Rossi M (2008) What emigration leaves behind: the situation of emigrants and their families in Ecuador. RES Working Papers 3244, Inter-American Development Bank, Research Department

Stock JH, Yogo M (2002) Testing for weak instruments in linear IV regression. NBER Technical Working Papers 0284, National Bureau of Economic Research, Inc

Taylor JE, Mora J (2006) Does migration reshape expenditures in rural households? Evidence from Mexico. Policy Research Working Paper Series 3842, The World Bank

Thomas D (1990) Intra-household resource allocation: an inferential approach. J Human Resour 25(4): 635-664

Working H (1943) Statistical laws of family expenditure. J Am Stat Assoc 38(221): 43-56

Zarate-Hoyos GA (2004) Consumption and remittances in migrant households: toward a productive use of remittances. Contemp Econ Policy 22(4): 555-565

doi:10.1186/2193-9039-2-1

Cite this article as: Göbel: Remittances, expenditure patterns, and gender: parametric and semiparametric evidence from Ecuador. IZA Journal of Migration 2013 2:1.

\section{Submit your manuscript to a SpringerOpen ${ }^{\circ}$ journal and benefit from:}

- Convenient online submission

- Rigorous peer review

- Immediate publication on acceptance

- Open access: articles freely available online

- High visibility within the field

Retaining the copyright to your article

Submit your next manuscript at $\triangleright$ springeropen.com 